\title{
Research on the Framework of Smart City Operating System Based on New ICTs
}

\author{
Wu Jun \\ Fiber Home Telecommunication Technologies Co., Ltd., Wuhan, China
}

Email address:

wujun@fiberhome.com

\section{To cite this article:}

Wu Jun. Research on the Framework of Smart City Operating System Based on New ICTs. American Journal of Artificial Intelligence. Vol. 4, No. 1, 2020, pp. 36-41. doi: 10.11648/j.ajai.20200401.14

Received: April 17, 2020; Accepted: May 18, 2020; Published: May 29, 2020

\begin{abstract}
With the deepening of Chinses national strategies such as Digital China and Artificial Intelligence, urban informatization is evolving from a smart city to a more advanced and super-intelligent system integrating urban governance with new information and communication technologies (ICTs) represented by artificial intelligence, big data, cloud computing. How to use the new ICTs to build the "smart city operating system" and other smart platforms to realize urban smartness has become the current research focus. First, this paper analyzes the four stages of the evolution of smart cities and the new ICTs that support urban agents. Second, taking the smart city planning of Wuhan Yangtze New City as an example, this paper introduces vision of Wuhan Yangtze New City, and analyzes the overall structure and smart infrastructure architecture of Wuhan Yangtze new smart city, and deeply studies the framework of the new ICTs-based Yangtze River Smart City operating system, including its compositions, integrated data architecture and application domain architecture. The third, how the new ICTs-based urban operating system can help cities achieve super-intelligence is also discussed. In addition, the paper suggested that Wuhan Yangtze New City should further improve its resilient urban planning for the future.
\end{abstract}

Keywords: Information and Communication Technologies (ICTs), Artificial Intelligence (AI), New Smart City, Urban Smart Agent, Super-intelligence System, Urban Operating System

\section{Introduction}

At present, featured with cloud computing, big data and artificial intelligence, information and communication technologies of the new generation, namely new ICTs, are giving birth to a new round of technological revolution and industrial transformation. Those technologies are also widely used in smart cities. Guided by the national development philosophy of "people-centric" and "innovative, coordinated, green, open and shared", a new round of smart city construction is emerging in China. How to use the new ICTs to build the "smart city operating system" and other smart platforms to realize urban smartness has become the current research focus [1-2]. The author has been deeply involved in the special planning of the new smart city of Wuhan Yangtze New City. This paper will take the planning of the new smart city of Wuhan Yangtze New City as an example to study and analyze the framework of the smart city operating system based on new ICTs.

\section{The Evolution of Smart City}

The main goals for China's new smart city are serving the people all the time, efficient and orderly urban governance, data opening and sharing, green and open economic development, and clear cyberspace security. At its essence, new smart city is a specific implementation to serve the people wholeheartedly [2].

\subsection{Four Stages of Urban Informatization Evolution}

While urban informatization evolved from City Teleport 1.0 to Digital City 2.0, the Smart City 3.0, its essence has not changed - it continues to promote in-depth new ICTs integration with urban construction, to make better use of two spaces of physical world and digital spaces, to fully develop both physical resources and data resources, and to move continuously towards the "dual city"- a city in the real world begin to have an increasingly clear digital reflection in the virtual world. The urban smart agents (super-intelligence 
systems) on this basis enable the city to think, drive, and improve on its own. Urban informatization has entered the smart agent era of 4.0, an advanced stage of new smart city. The development process of urban informatization is shown in Figure 1 [3-4].

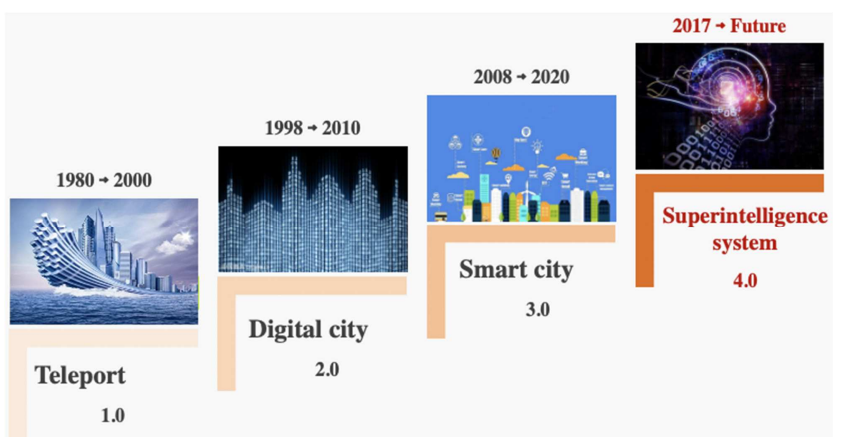

Figure 1. The development course of city informatization.

\subsection{S-ABCD Technology to Support Urban Smart Agent}

The new ICTs supporting urban smart agent can be summarized as "3S-ABCD [3-4]: "3S" means Software definition, SDN/NFV, and open Source. "A" refers to the Artificial intelligence of the network. "B" refers to Big data and Block chain. " $\mathrm{C}$ " refers to the Cloud. "D" refers to Digital twin. The 3S-ABCD technology that supports the urban smart agent is shown in Figure 2.

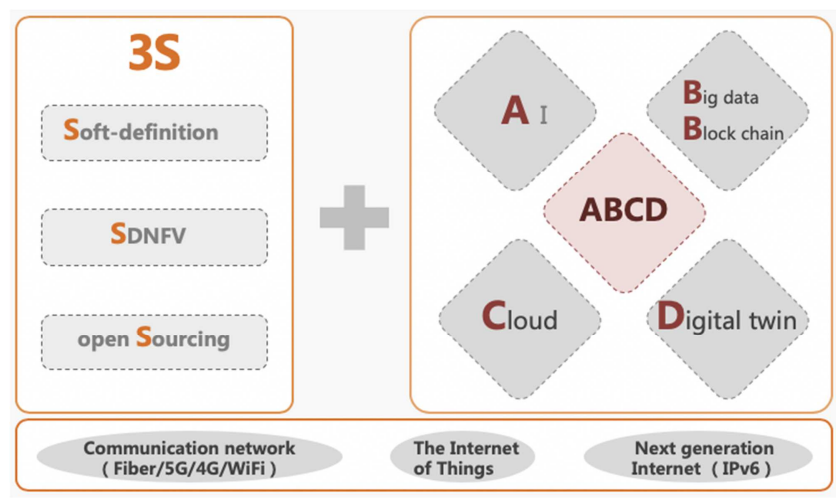

Figure 2. 3S-ABCD technology to support urban agent.

\subsection{The Core Platform of Urban Smart Agent -- City Operating System}

With the rise of artificial intelligence technology, after smart city and smart earth, a brain with a neural layer is gradually embedded between human society and the natural world, forming digital twins. Human activities become more intelligent and informalization, and more and more tend to become super urban smart agents [4-5].

As shown in Figure 3, the urban operating system is based on new ICTs such as artificial intelligence. It takes data as the core element, realizes intelligent decision-making through unified data aggregation and data driving, and is the source and driving force for realizing urban smartness [6-8].

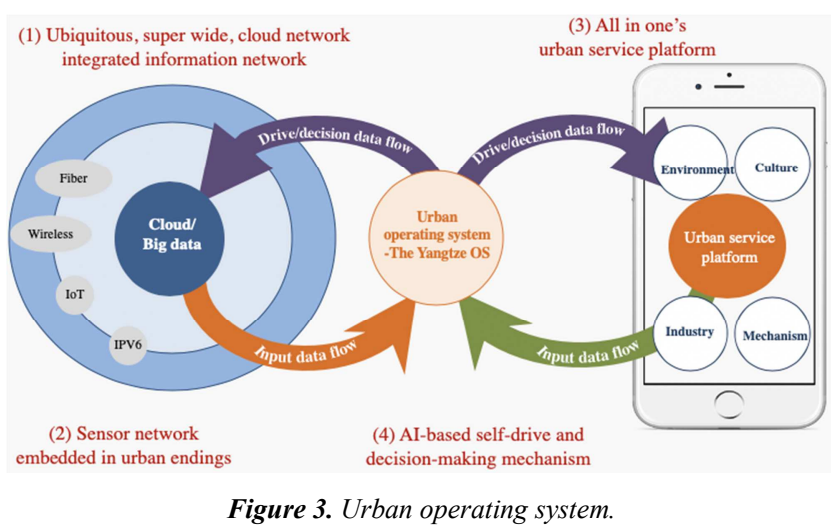

\section{Overview of the New Smart City of Yangtze River New City}

\subsection{Positioning of Yangtze River New City}

In early 2017, The 13th Wuhan People's Congress proposed to plan and build a new city - Wuhan Yangtze River New City. The plan puts the new city in juxtaposition with Xiong'An New Area, demanding that the city should be built with international standards meanwhile maintaining Chinese characteristics. The constructions follow a 3-step strategy: starting with an area of 50 square kilometers, then 100 square kilometers of development area, and 500 square kilometers being the forward control area. All efforts should be put in so that Wuhan Yangtze River New City becomes an innovative city, an ecological green city, a city of international friendship, a big city which creates wealth, and a role model in practicing the concepts of modern smart city development [6].

\subsection{The New Smart City Positioning of Yangtze River New City}

Through digital twin technology, Wuhan Yangtze River New City plans to build two new cities simultaneously, one being the physical city, other being the digital intelligent city. The positioning of the Yangtze River Smart City is to become the fifth city above the four cities of "innovation city, international friendship city, green city and wealth city" - a modern smart city based on the next generation of information technology and application.

The overall goal of Yangtze River Smart City planning is to focus on the demand of Yangtze River New City in the next 50 years, based on the organic integration of intelligent new city and physical new city, to build the world's leading Yangtze New City information infrastructure, application system and industrial ecology, to build to become an urban intelligence agent with the main features of "whole-domain communication, data sharing, intelligent decision-making, people's livelihood, industrial upgrading and security guarantee", to strive to become the world's leading new smart city construction demonstration area [7]. 


\section{An Analysis on the New ICTs-based Yangtze River Smart City Operation System}

\subsection{The Overall Structure of Yangtze River Smart City}

The overall structure of Yangtze River Smart City is mainly composed of 6 parts: infrastructure architecture, data integration architecture, application domain architecture, standard evaluation architecture, construction operation architecture and development environment architecture [910], as shown in Figure 4.

The infrastructure architecture is the foundation of operation and development of the Yangtze River Smart City. By digitizing and intelligently processing the urban resource elements, the infrastructure architecture promotes the efficiency, convenience, innovation and coordination of the functional elements of city operation. The data integration architecture is the key to the construction and development of the Yangtze River Smart City. Through the connection of data collection, data sharing and exchange, data storage, data analysis, service support, data opening and other links, a coordinated and integrated application system of the entire informatization supply chain is constructed. The architecture of the application field is the embodiment of the construction effect of the Yangtze River Smart City, serving the four main bodies of the city, the government, enterprises and citizens. The development environment architecture, standard evaluation architecture, construction and operation architecture run through and serve the three-tier architecture of infrastructure, data aggregation, and application fields.

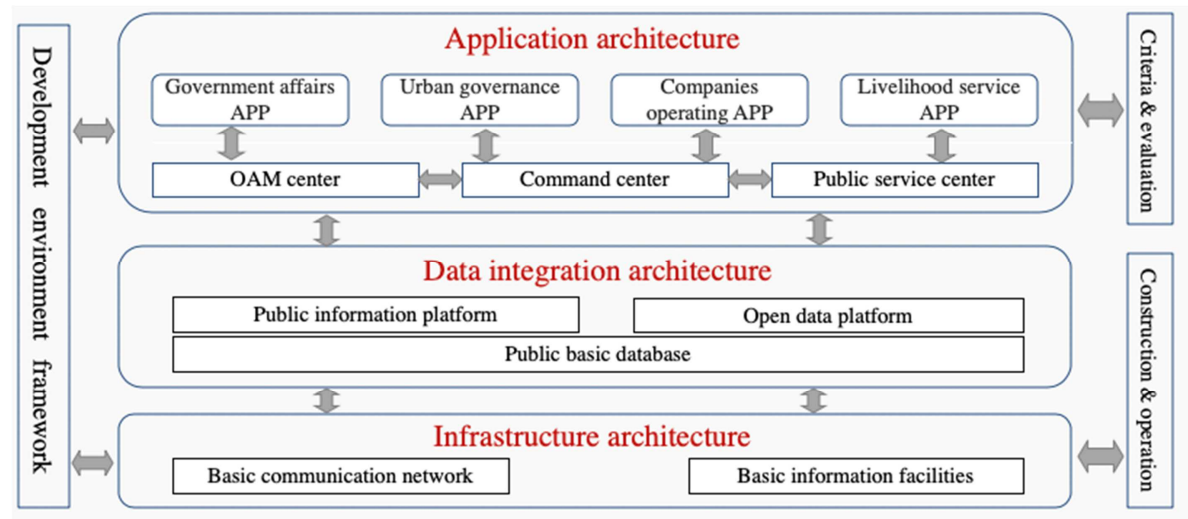

Figure 4. The overall structure of Yangtze River Smart City.

\subsection{Infrastructure Architecture of Yangtze River Smart City}

According to the top-level architecture, Wuhan Yangtze River Smart City smart infrastructure is designed as "1 $+1+1(\mathrm{~N})+$ $1 "$ architecture [6-8], as shown in Figure 5.

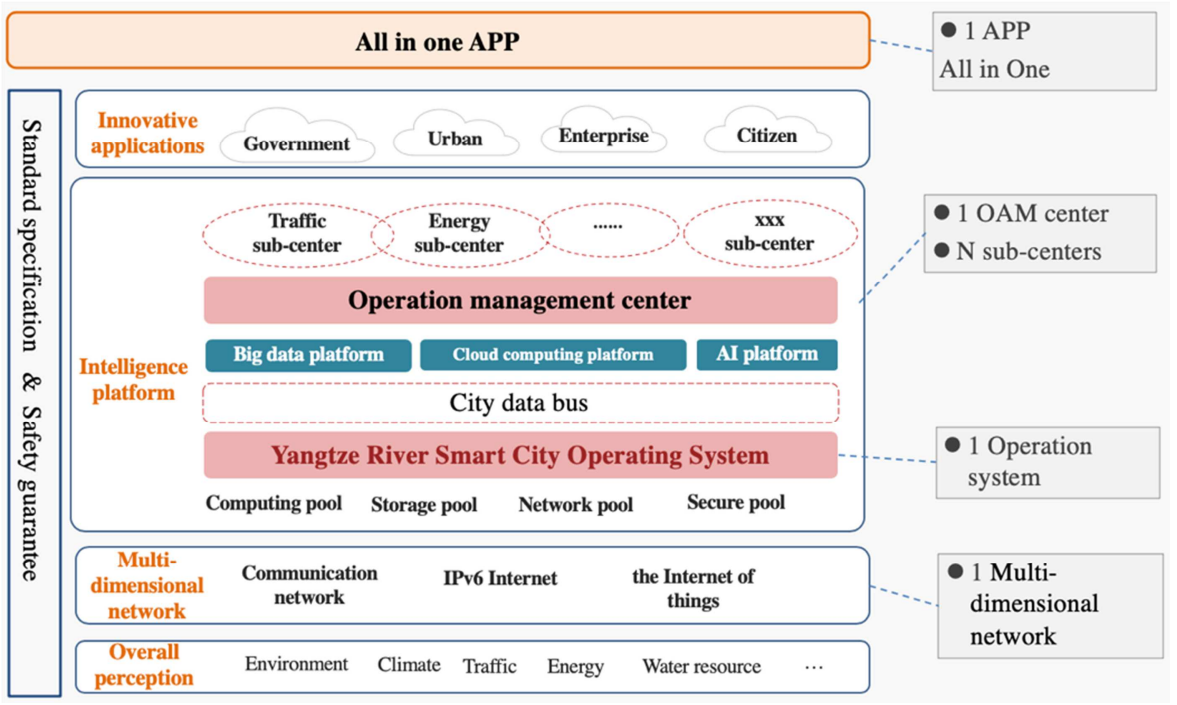

Figure 5. The architecture of Yangtze River Smart City smart infrastructure.

The first "1" refers to a multi-dimensional network, which is the nerve center and nerve endings of the Yangtze River
Smart City, realizing the comprehensive information interconnection of the Yangtze River Smart City and forming 
the foundation of a digital world.

The second "1" refers to the Yangtze River Smart City Operating System-Changjiang OS, which is the heart of the Yangtze River Smart City. As the core of realizing smartness in Yangtze New City, Changjiang OS provides a unified data and resource underlying framework for cloud computing platform, big data platform, internet of things platform and AI platform in Yangtze River New City through resource synthesis, data integrations, standardized applications and service interfaces.

The third "1 $(\mathrm{N})$ " refers to the operation and management center of Yangtze River Smart City, and N sub-centers. As the portal of Yangtze River Smart City, it coordinates the urban planning, construction and operation of each link, constituting a new urban management service system.

The last "1" refers to the integrated applications. The public can enjoy all the services of " Yangtze River Smart City" through one entrance, realizing the full coverage of all kinds of services of government management, city governance, enterprise operation and citizens' life.

\subsection{Smart City Operating System Framework of Yangtze New City}

\subsubsection{The Composition of Yangtze River Smart City Operating System}

The composition of Yangtze River Smart City operating system-Changjiang OS, as shown in Figure 6, consists of one basic platform cloud management platform, three data platforms-data sharing and exchange platform, artificial intelligence platform, big data platform, and two application platforms-application development platform and application support platform. Safety operation and maintenance system, standard and specification system provide support for Changjiang OS. Changjiang OS, based on technologies such as artificial intelligence and big data, is the brain of Wuhan Yangtze River Smart City [7, 11-13].

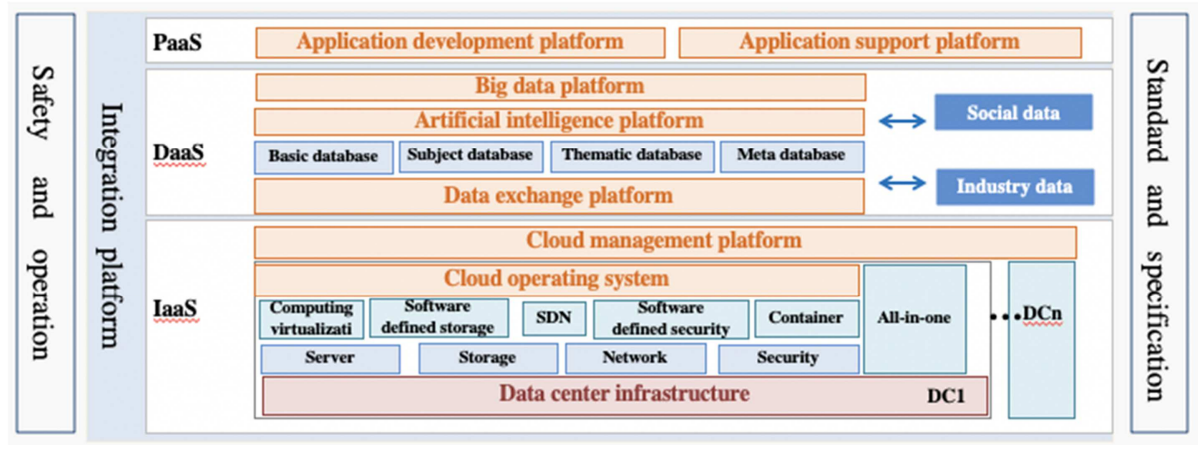

Figure 6. The composition of Changjiang OS.

\subsubsection{Data Integration Architecture Based on Changjiang OS}

The data integration architecture of Yangtze River Smart City is shown in Figure 7. Through data aggregation, the intelligent application can not only ensure the generation of data, but also achieve the continuous construction of data. In order to realize data-driven full life cycle management as well as to build the technology and data ecology of the city, it is necessary to develop management standards related to data assets, for example, urban data asset management specification (including data asset management mode/system/method, data object naming specification, etc.) [7].

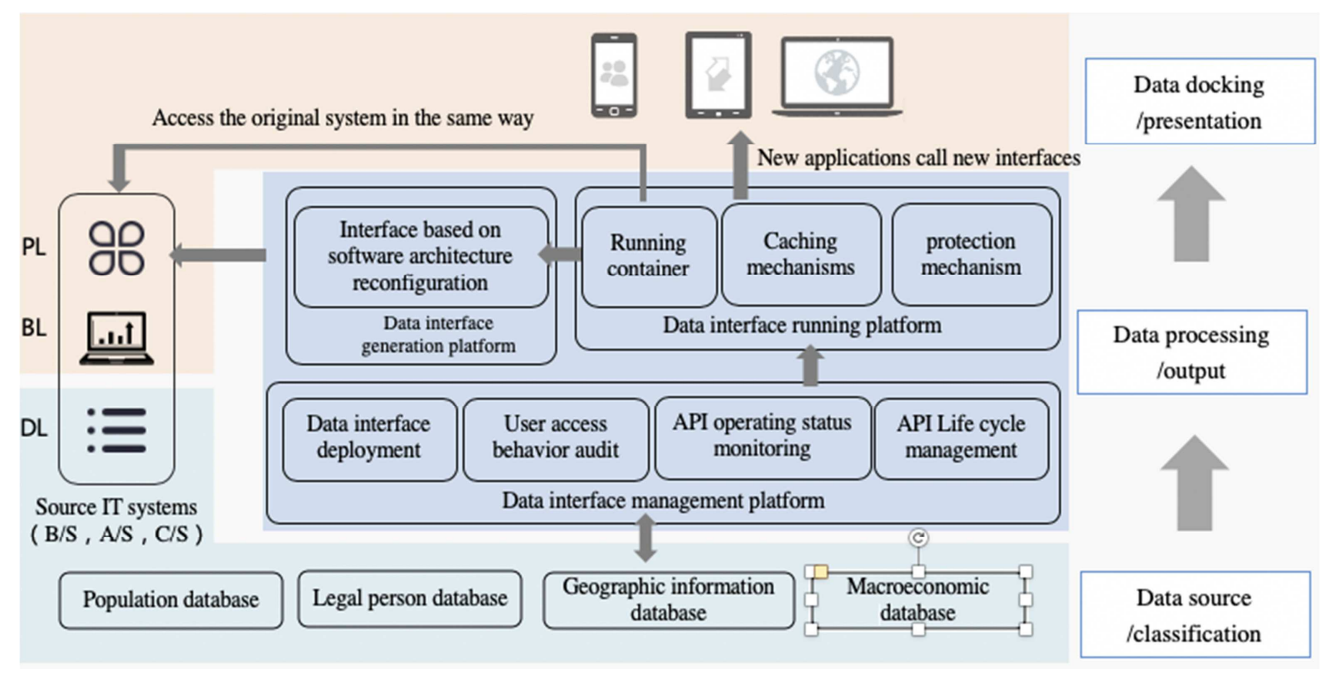

Figure 7. The data integration architecture of Yangtze River Smart City. 


\subsubsection{Application Domain Architecture Based on Changjiang $O S$}

The architecture of the application field of Yangtze River Smart City is shown in Figure 8. The key points are: to build the platform layer of docker, to use micro-service mode, and to provide a capability engine. The capability engine provides rapid application delivery and make it possible to build capabilities to build an open-source and smart application ecosystem. It provides services to governments, cities, enterprises and citizens, and supports various innovative applications [7, 14].

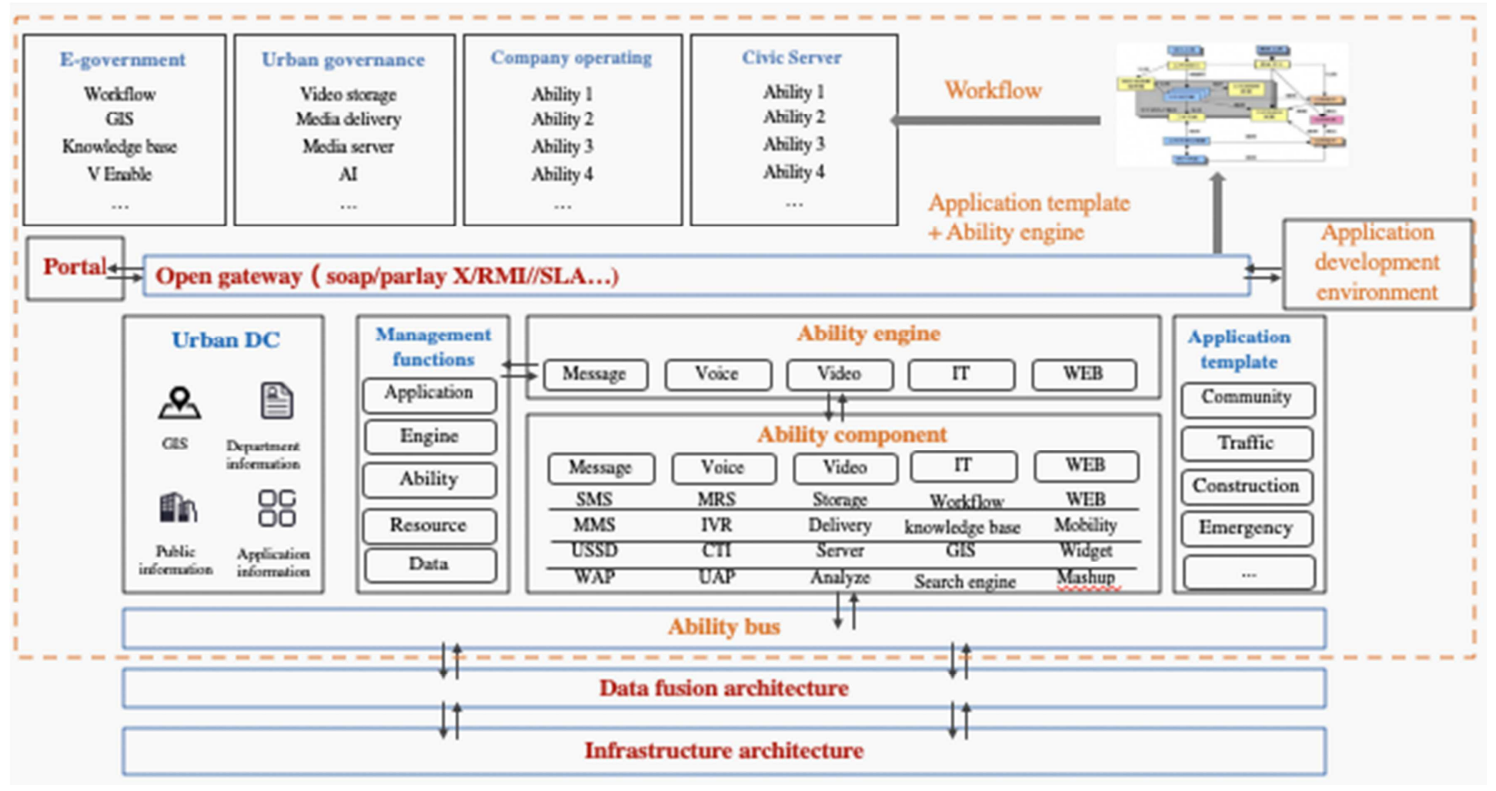

Figure 8. Application domain architecture based on Changjiang OS.

\subsubsection{Operation Management Center Based on Changjiang OS}

The operation and management center is responsible for operation perception, comprehensive monitoring of the city and providing early warning, inter-departmental emergency response linkage, and the decision support of city management. The operation management center of the physical entity is composed of one total operation center and $\mathrm{N}$ sub-centers. The sub-centers are built to meet the requirements of specific situations, such as the government operation center, the traffic operation center, the pipe corridor operation center, the safety operation center, etc. The operation center is responsible for centralized display of city information; the $\mathrm{N}$ sub-centers are responsible for calculation, analysis, decision support and other functions [8].

\subsubsection{Gradual Realization of Urban Intelligence Based on Changjiang $O S$}

The super intelligent agent of the new smart city cannot be achieved overnight. The application of artificial intelligence technology such as deep reinforcement learning in smart cities is also developing [15]. It is suggested that the urban intelligence based on Changjiang OS should be gradually implemented in three stages. In the initial stage, urban intelligence is realized by "manual judgment, manual execution and machine-assisted analysis". In the intermediate stage, urban intelligence is realized by "judgement and giving advice mainly by machine, making decisions and executing manually". In the advanced stage, urban intelligence is realized by "machine making independent judgment and executing automatically, giving the human prompt and forming the operation record" [8].

The urban intelligence based on the Changjiang OS can be reflected in various aspects, such as controlling the rotation of the camera at a certain intersection, intelligent control of traffic lights, energy consumption acquisition, and adaptive tuning of smart buildings. Even according to the big data of urban resource consumption, the government can be prompted to formulate policies and measures for the convenience of the people.

\section{Conclusion}

With the continuing progress on the national strategies such as promoting Digital China and Artificial Intelligence, urban informatization is evolving from smart city to more advanced super-intelligent agents which integrate urban governance with new ICTs represented by artificial intelligence, big data, and cloud computing. The AI-based urban operating system which takes data as the core element, realizes intelligent decision-making through unified data aggregation. It is the source and driving force for realizing urban smartness - super intelligent agents.

The special plan for the new smart city of Wuhan Yangtze New City has been approved by national experts in July 2019 and approved by the government at all levels. It will be built gradually and in stages. The novel coronavirus outbreak at 
the beginning of 2020 exposed the deficiencies in the construction of smart cities. We need to re-examine and improve the planning for a smart city so that it has rapid analysis, better response to and treatment of sudden plagues and social conflicts, and more rapid recovery of production capacity, etc. It is suggested that Wuhan Yangtze New City should further improve its resilient urban planning for the future.

Wuhan Yangtze River New City is a role model of a new smart city, which is planned by Wuhan to "gather the national strategy, inherit the Yangtze River civilization and carry the mission of Wuhan". Changjiang OS, the smart city operating system that is expected to fully supplement the urban resilience elements, helps Yangtze River New City achieve its super-intelligence through the implementation of ultrawide urban network, the deployment of ubiquitous devices embedded into city nerve endings to collect massive amount urban data, and through the self-driven decision-making mechanisms based on artificial intelligence such as deep reinforcement learning.

\section{References}

[1] Chinese Society for Urban Studies. City science and the city of the future $[\mathrm{M}]$. Beijing: Science and technology of China press, 2016.

[2] CHEN C, CUI Y, ZHANG Y X, et al. Research report on the development and practice of new smart city [R]. Beijing: China academy of information and communications, China telecom group co. LTD, 2018.

[3] WU J. Practicing digital transformation by developing new smart city business [J]. Journal of Electrical and Electronic Engineering, 2018, 6 (6): 160-163.

[4] Yu S H. A new paradigm of future network: Net-AI agent and city-AI agent [J]. Study on optical communications, 2018, (6): $1-8$.

[5] Datta, S. P. A. (2016). Emergence of digital twins [J]. arXiv preprint arXiv: 1610.06467 [cs. CY].
[6] Shanghai Tongji planning and design institute. Study on master plan of Wuhan Yangtze River New City [R]. Wuhan: Wuhan Yangtze River New City management committee, 2018.

[7] WU J. Wuhan Yangtze New City smart city special planning research [R]. Wuhan: FiberHome Telecommunication Technologies Co., Ltd., 2019.

[8] WU J. Wuhan Yangtze New City smart city special planning research [C]. Proceedings of the China automation conference 2019 (CAC2019), 2019.

[9] Standardization Administration of the People's Republic of China. Top-level design guide for smart cities, GB/T363332018 [S]. 2018.

[10] YU J S, LIN K, HUANG Z H, et al. Smart city — top-level design and practice [M]. Beijing: Posts \& Telecom Press, 2017.

[11] ZHANG J F, HUA X S, HUANG J Q, et al. City brain: practice of large-scale artificial intelligence in the real world [J]. IET Smart Cities, 2019, doi: 10.1049/iet-smc.2019.0034 www.ietdl.org.

[12] China academy of information and communications. Urban big data white paper [R]. Beijing: China academy of information and communications, Big data technical standard promotion committee of China telecommunication standardization association, 2019.

[13] CRONEMBERGER F, GIL-GARCIA J R. Big data and analytics as strategies to generate public value in smart cities: proposing an integrative framework $[\mathrm{M}]$. Switzerland: Springer Nature, 2019.

[14] Merkel, D. (2014) Docker: Lightweight Linux Containers for Consistent Development and Deployment. Linux Journal, 2014, No. 2.

[15] Mehdi Mohammadi, Ala Al-Fuqaha, Mohsen Guizani, et al. Semisupervised Deep Reinforcement Learning in Support of IoT and Smart City Services [J]. IEEE Internet of Things Journal (IF 9.515), 2017, doi: 10.1109/jiot.2017.2712560. 